\title{
Axiological approach to developing spirituality and morality in the process of L2 PR education
}

\author{
Alla P. Minyar-Beloroucheva ${ }^{1^{*}}$, Polina I. Sergienko ${ }^{2}$, Olga D. Vishnyakova ${ }^{3}$, \\ Elizaveta A. Vishnyakova ${ }^{4}$, and Oksana G. Anossova ${ }^{5}$ \\ ${ }^{1}$ Lomonosov Moscow State University, History Faculty, Department of Foreign Languages, Moscow, \\ Russia \\ ${ }^{2}$ Lomonosov Moscow State University, Faculty of Foreign Languages and Area Studies, Department \\ of English for Humanities Faculties, Moscow, Russia \\ ${ }^{3}$ Lomonosov Moscow State University, Philological Faculty, Department of English Linguistics, \\ Moscow, Russia \\ ${ }^{4}$ Lev Tolstoy Tula State Pedagogical University, Faculty of Foreign Languages, Department of the \\ English Language, Tula, Russia \\ ${ }^{5}$ Peoples' Friendship University of Russia, Engineering Academy, Moscow, Russia
}

\begin{abstract}
The article is devoted to the analysis of fundamental aspects of spiritual and ethical education as well as to the development of cultural and moral values, pertaining to global citizens and proponents of sustainable development in the system of undergraduate PR education. The authors view the issues dealing with fostering the feelings of duty, breeding responsibility before other people and the environment, respect for human rights and freedoms as well love and deference for one's family, the country and the whole world in the process of L2 PR studies. An individual trajectory chosen for L2 PR undergraduates' needs and capabilities focuses on their intellectual as well as cultural development, thereby serving the purpose of enhancing their individual qualities. The spiritual image and values of L2 PR undergraduates are influenced by all the global problems of our time, including understanding life as the greatest value, preserving the world, the environment, and the entire cultural heritage. Spirituality implies a certain state of human self-awareness to make the one find new expressions in thoughts, in language and actions. This is the foundation for building a healthy and strong society and nations. Online extracurricular activities allow the educators to form not only the basic social, moral and cultural values that guide society, but also contribute to the personal growth of young people, their formation as individuals, the realization of all their potentials and abilities.
\end{abstract}

Keywords: spiritual and moral values, aspects of education, L2, PR undergraduates.

\footnotetext{
*Corresponding author: ostvera@mail.ru
} 


\section{Introduction}

At present, under the complicated circumstances of the world development, the issue of the basic value of human existence has gained special prominence. A necessary prerequisite for the formation of spirituality, cultural and national traditions and the development of human personality does not only deal with historical experience, spiritual potential and centuries-old cultural heritage, but also with self-education, communication and collaboration in the system of social relations and education for environmental protection. The process of values upbringing requires the mobilization of spiritual and moral features as well as actualization of cultural heritage. The issue of instilling these qualities in the young generation modern education is gaining momentum, the non-linguists' cultural education should be considered $[1,2]$. This is due to the fact that at this stage of society development, there takes place the process of axiological reassessment when universal values are being challenged, followed by the crisis of spiritual and moral development not only of civilization as a whole, but also of individuals, their inner world and aspirations for the future. Undergraduates studying public relations, generally abbreviated to PR [3], who are on the threshold of active participation in the formation of global agenda and promoting certain interests at the global level seek to change the real meaning of life.

\section{Methods and methodology}

There exist various approaches to the study of the issues related to the formation of spiritual and moral foundations, among which it is possible to distinguish the method of analysis and synthesis, synergetic, functional, comparative-historical methods, as well as the methods of observation and active participation [4]. The most significant is the axiological approach, which is the basis of ethical theories and is inseparably connected with the concept of value.

\section{Results and discussion}

Teaching L2 to PR undergraduates should not be limited to learning vocabulary and grammar forms [5]. The formation of spiritual and moral values and the development of individual qualities must be carried out along with the acquisition of knowledge, skills and competences by the PR undergraduates. This approach radically changes the meaning of education, which is to awaken the activity of PR undergraduates as individuals, to promote their spirituality, the will to learn independently and constantly improve their performance.

Every person has individual traits and qualities including intellectual, moral, emotional and volitive ones, which are determined by society as a whole, as well as framed in the process of family, interaction, social, cultural and professional activities of the individual Business and professional communication should be built on the basis of such moral qualities of the individual and categories of ethics as honesty, truthfulness, modesty, generosity, duty, conscience, dignity, honor, which endow business relations with a spiritual and moral character. In the process of L2 teaching to PR undergraduates it is important to create all the necessary conditions to instill their creative and spiritual capabilities, mental health and morality, adequate perception of the world and their place in it. During practical classes for L2 PR undergraduates activators inoculate spiritual and moral values, civic duty and a sense of global citizenship.

The moral aspect implies not only a vision and understanding of the natural beauty and the cultural heritage of the whole world, but it also contributes to the formation of a scientific worldview based on knowledge about the cultural heritage of humanity and its inherent laws. Teaching the ethical culture is determined by the universal meaning of culture in the broad 
sense of the word for a person and society and includes knowledge about the components and their relationships in the "person-society-culture" system, as well as the moral and aesthetic attitude. This is closely related to spiritual and moral education, which characterizes the degree of acquisition by L2 PR undergraduates of the moral experience of society, the degree of implementation of this experience in behavior and in relation to other people. L2 PR undergraduates develop the ability to express themselves and their feelings, determination to reach the goal and assess the result of the work performed. This allows you to cultivate the will and responsibility for your actions.

The civic component of education contributes to the formation of a person conscious about their individual achievements in line with sustainable development, who has respect for the cultural heritage and science creators, ensuring the leading role of science and art in society, understanding the need for their reasonable use and further human society development. This also includes the usage of the acquired knowledge and skills to solve urgent problems in life, mastering PR methods and the ability to use them efficiently in practice. The idea of global citizenship within L2 PR education presupposes the leading role of the globalizing world and the necessity to treat the planet as a global interconnected and interdependent village.

The formation of a healthy lifestyle and culture of behavior in the environment are necessary for the harmonious development of the individual assessing the consequences of their activities. The healthcare aspect is of primary importance during the coronavirus pandemic. It involves the formation of a healthy lifestyle, an environment friendly behavior; mastering the skills to assess the PR undergraduates' activities in relation to the environment, other people's health and body, the development of socially significant personal qualities that can resist antisocial behavior; instilling scientific, humane, charitable views on their health, the health of others and future generations.

During L2 professionally oriented PR education it is essential to develop 6Cs competences, that include character, collaboration, communication, creativity, critical thinking, citizenship [6]. These competences can be achieved by teamwork ready to fulfill creative tasks. PR is a multi-faceted discipline that embraces the broadest scope of problems dealing with the whole world. It permits to tackle various aspects of human life, forming spirituality and morality [7, 8] within PR undergraduates. However, "for public relations, like so many tools, the morality is in how it is used and to what purpose it is put, rather than just in its existence or its potential. An ethical practitioner will understand how that potential is managed or even controlled" [9: 74].

Due to the saturation of PR undergraduates with information and lack of time at practical classes, educators should help them to shape their cultural values during extracurricular work. At the time of Covid-19 pandemic PR undergraduates participate in web-round-table discussions, go on digital excursions to the museums and exhibitions online. Isolated and under the lockdown, PR undergraduates should be virtually together, coordinated by the tutor. However, all these online activities cannot substitute offline life, they still nourish the PR undergraduates' urgent needs in communication, which are indispensable for selfdevelopment and self-affirmation in a peer group. Team work generates different attitudes to studying as they are determined by the combination of personal and public interests. PR undergraduates eagerly share and exchange their ideas, interests and career plans with their mates. Friendly relations create a favorable ground for personal understanding and implementation of the future specialist's spiritual and moral culture and its main components.

This creates, to some extent, favorable conditions for the PR undergraduates' inclusion in the system of real moral relations, mutual assistance, responsibility, and their goals, develops their individual capabilities and creativity. When offered an ethical dilemma to discuss PR undergraduates should be able to develop a common strategy to solve all the rivalling sides and meet of the competing needs and aspirations. It also required to acquaint 
PR undergraduates with the existing codes of professional ethics, like Chartered Institute of Public Relations Code of Conduct [10] or the PRSA Code of Ethics, complied by Public Relations Society of America [11] to ask them to group most efficient rules and identify potential weaknesses.

\section{Conclusion}

National values being variable, it is necessary to reconcile the distinctions and develop a universal code of spiritual and moral values which can be recognized and implemented during L2 PR undergraduate education as ethical and aesthetical guidelines for their future professional purposes. Thus, the task of spiritual and moral formation is an urgent challenge in the process of preparing future PR councellors. The realization of personal prospects is possible on the basis of high-quality education. It means that while teaching PR undergraduates, university lecturers, teachers, activists and tutors should pay special attention to the process of spiritual and moral education, whose priorities are persistence, citizenship, respect for freedom and human rights, responsibility for the environment, love for the family, the country and the world. The higher the spiritual and moral culture of PR undergraduates, the higher its social relevance and social significance for society.

\section{References}

1. O. Anossova, (2020), LNNS IEEHGIP, 131, 367-3756 (2020). https://doi.org/10.1007/978-3-030-47415-7_39

2. O. Vishnyakova, A. Minyar-Beloroucheva, P. Sergienko, E. Vishnyakova, Harmonizing different cognitive styles through reading, in Proceedings of the 5th International e-Conference on Studies in Humanities and Social Sciences, 5IeCSHSS, 24-28 June 2020, Ruse, Bulgaria, 17-30 (2020). https://doi.org/10.32591/coas.econf.05.02017v

3. A. Minyar-Beloroucheva, P. Sergienko, E. Vishnyakova, O. Vishnyakova, International Journal of English Linguistics, 10(1), 26-36 (2020). https://doi.org/10.5539/ijel.v10n1p26

4. L.S. Vygotsky, Mind in society: the development of higher psychological processes (Harvard University Press, Cambridge MA, 1978)

5. A. Minyar-Beloroucheva, P. Sergienko, E. Vishnyakova, O. Vishnyakova, European Proceedings of Social and Behavioural Sciences, 97, 539-547 (2020). https://doi.org/10.15405/epsbs.2020.12.02.72

6. M. Fullen, J. Quinn, J. McEachen, Deep Learning: engage the world change the world (Corwin Press, Thousand Oaks, CA, 2017)

7. A. Gregory, Ethics and professionalism in public relations, in R. Trench, L. Yeomans (Eds.), Exploring public relations (Pearson, London, 2009)

8. M. S. Neill, Research Journal of the Institute for Public Relations, 3(1), 1-25 (2016)

9. S. Wolstenholme (Ed.), Introduction to Public Relation (Pearson Education Limited, London, 2013)

10. CIPR Code of Conduct, (n.d.). Accessed on: October 10, 2020. [Online]. Available: https://www.cipr.co.uk/CIPR/About_Us/Professional_standards/CIPR/About_Us/Profe ssional_Standards.aspx?hkey=653e8542-2926-4027-9af0-a092d4fcaa79

11. PRSA Code of Ethics (n.d.). Accessed on: October 10, 2020. [Online]. Available: https://www.prsa.org/about/prsa-code-of-ethics 